\title{
Article
}

\section{Relationships between Physical Activity, Work Ability, Absenteeism and Presenteeism in Australian and New Zealand Adults during COVID-19}

\author{
Jayden R. Hunter ${ }^{1, *(\mathbb{D},}$, Rebecca M. Meiring ${ }^{2,3}{ }^{1}$, Ashley Cripps ${ }^{4}$, Haresh T. Suppiah ${ }^{5}{ }^{\circledR}$, Don Vicendese ${ }^{6,7}$, \\ Michael I. Kingsley ${ }^{1,2}\left(\mathbb{D}\right.$ and Brett A. Gordon ${ }^{1}(\mathbb{C}$
}

check for

updates

Citation: Hunter, J.R.; Meiring, R.M.; Cripps, A.; Suppiah, H.T.; Vicendese, D.; Kingsley, M.I.; Gordon, B.A. Relationships between Physical Activity, Work Ability, Absenteeism and Presenteeism in Australian and New Zealand Adults during COVID-19. Int. J. Environ. Res. Public Health 2021, 18, 12563. https:// doi.org/10.3390/ijerph182312563

Academic Editors: Gemma Ryde and Simone A. Tomaz

Received: 18 October 2021

Accepted: 23 November 2021

Published: 29 November 2021

Publisher's Note: MDPI stays neutra with regard to jurisdictional claims in published maps and institutional affiliations.

Copyright: (c) 2021 by the authors Licensee MDPI, Basel, Switzerland This article is an open access article distributed under the terms and conditions of the Creative Commons Attribution (CC BY) license (https:/ creativecommons.org/licenses/by/ $4.0 /)$
1 Holsworth Research Initiative, La Trobe Rural Health School, La Trobe University, Bendigo 3552, Australia; Michael.kingsley@auckland.ac.nz (M.I.K.); b.gordon@latrobe.edu.au (B.A.G.)

2 Department of Exercise Sciences, Faculty of Science, University of Auckland, Auckland 1023, New Zealand; rebecca.meiring@auckland.ac.nz

3 Movement Physiology Research Laboratory, School of Physiology, University of the Witwatersrand, Johannesburg 2193, South Africa

4 School of Exercise and Health Sciences, University of Notre Dame Australia, Fremantle 6160, Australia; ashley.cripps@nd.edu.au

5 Sport and Exercise Science, School of Allied Health, Human Services and Sport, La Trobe University, Melbourne 3086, Australia; H.Suppiah@latrobe.edu.au

6 Department of Mathematics and Statistics, La Trobe University, Bundoora 3086, Australia; don.vicendese@unimelb.edu.au

7 Melbourne School of Population and Global Health, University of Melbourne, Carlton 3053, Australia

* Correspondence: j.hunter@latrobe.edu.au

Abstract: Public health movement and social restrictions imposed by the Australian and New Zealand governments in response to the COVID-19 pandemic influenced the working environment and may have affected health behaviours, work ability, and job performance. The aim of this study was to determine the associations between health behaviours and work ability and performance during COVID-19 restrictions and if health behaviours were related to demographic or population factors. A cross-sectional survey was used to gather responses from 433 adult employees in Australia and New Zealand between June and August 2020. The survey requested demographic information and used the International Physical Activity Questionnaire, Work Ability Index, and the World Health Organisation's Health and Work Performance Questionnaire. Multivariate regression models were used to explore relationships between the identified variables while controlling for several possible confounders. Being sufficiently physically active was associated with higher reported physical (aOR $=2.1 ; p=0.001)$ and mental work abilities $(\mathrm{aOR}=1.8 ; p=0.007)$ and self-reported job performance (i.e., lower presenteeism) (median $+7.42 \% ; p=0.03$ ). Part-time employees were $56 \%$ less likely $(p=0.002)$ to report a good or very good mental work ability. Those with existing medical conditions were $14 \%$ less likely $(p=0.008)$ to be sufficiently active and $80 \%$ less likely $(p=0.002)$ to report rather good or very good physical work ability. Being sufficiently active was associated with higher physical and mental work abilities and better job performance during the COVID-19 pandemic. Employers should support opportunities for regular physical activity and provide specific support to individuals with medical conditions or in part-time employment.

Keywords: exercise; physical activity; coronavirus; productivity; employee; work ability; health promotion

\section{Introduction}

In response to coronavirus disease (COVID-19), a contagious condition first identified in December 2019, some world governments put in place stay-at-home orders and other movement and social restrictions to minimise the spread of the virus. Movement 
restrictions varied between New Zealand and Australian states and territories as both countries pursued a suppression or elimination policy, with restrictions including the temporary closure of public spaces and gyms, shops, businesses, schools, and tertiary institutions. In addition, many employees were encouraged or required to work from home, with only essential workers able to continue transiting to the workplace. This is likely to have resulted in changes to employment and health behaviours. Findings from studies across a range of countries indicate that community-wide PA participation decreased [1,2], sedentary behaviour increased [1,3], and poorer mental wellbeing was associated with lower activity levels during this time $[1,2,4,5]$. These behaviours have important health ramifications, as regularly engaging in sufficient amounts of physical activity (PA) and minimising sedentary behaviour is beneficial for health and important for preventing and managing chronic diseases [6,7]. The World Health Organization recommends that adults engage in 150-300 min of moderate-intensity or 75-150 min of vigorous-intensity PA (or a combination of both) each week, with muscle-strengthening exercise performed on at least 2 days [8]. Even before the pandemic, however, less than one half of all adults globally met these guidelines [9], and in Australia, only 15\% of adults reported meeting both the aerobic and strength exercise guidelines on a weekly basis [10,11]. This poses a serious public health problem, as physical inactivity is a leading cause of chronic disease, morbidity, and premature mortality and adds to the global economic burden [12].

Based on previous research, it could be theorised that the reduction in PA during the COVID-19 pandemic could negatively impact work ability and job performance. In an occupational context, physical inactivity is estimated to cost INT\$14 billion in lost productivity globally each year [12] and is associated with lower physical and mental work ability $[13,14]$. However, systematic reviews conducted before COVID-19 reported that regular exercise may increase work ability [15] and reduce absenteeism and presenteeism [16]. These are important findings, as productivity losses due to chronic disease-related absenteeism (i.e., poor health resulting in sick leave) and presenteeism (i.e., when a person at work is unable to perform at full capacity due to illness, stress, or other issues) represent $10-15 \%$ of global economic output [17]. Recent evidence suggests a favourable relationship between higher MVPA and lower absenteeism when accounting for various health factors. Observational (each weekly hour of reported PA was associated with the equivalent of 1.2 days per year lower sickness absence amongst Spanish university employees [18]) and interventional data [19] demonstrate positive outcomes for both absenteeism and presenteeism following weekly vigorous intensity aerobic and strength exercise. While findings are not ubiquitous [15], there is evidence demonstrating improved physical and mental work ability following exercise interventions [20,21]. Exercise, therefore, has the potential to mitigate the chronic disease risk associated with sedentary occupations, reduce employee absenteeism and presenteeism, and improve work ability [16]. However, whether relationships between PA, work ability, and job performance exist when various community-wide movement and social restrictions are in place is unknown.

The aim of this study was to investigate if Australian and New Zealand employees who were meeting aerobic and strength exercise guidelines reported higher work ability and lower work-related absenteeism and presenteeism than physically inactive employees during the COVID-19 pandemic, which was being managed with various movement and social restrictions.

\section{Materials and Methods}

\subsection{Participants and Recruitment}

A cross-sectional study design was used to collect self-reported data. Australian and New Zealand adults were invited to participate in an online survey using REDCap (version 10.0.29, Vanderbuilt University, Nashville, TN, USA) a secure, web-based software platform designed to support data capture for research studies [22,23]. The survey was advertised through La Trobe University, University of Auckland, and University of Notre Dame Australia research newsletters and social media networks, local news media, and 
online community noticeboards from 9 June-9 August 2020. This recruitment period was selected to maximise the response of a broad representation of the targeted population, and multiple avenues of participant recruitment were deliberately chosen to engage a diverse range of participants from broad demographic backgrounds. A total of 456 respondents completed the survey. During this period, different movement and social restrictions were in place across Australia's states and territories, placing various limitations on group sizes for gathering indoors and outdoors.

In New South Wales in June, people could meet outside in groups of up to 20, up to 100 people were allowed inside gyms, and indoor gym classes allowed up to 10 people, providing there was only one person per four square meters. From 1 July, restrictions eased such that there was no upper limit on the number of people allowed at an indoor venue, with the four square meter rule still in place. In Victoria, outdoor exercise classes were limited to 10 people, with no sharing of equipment and $1.5 \mathrm{~m}$ distancing between people. From 30 June, residents across Melbourne and surrounding postcodes entered a period of lockdown and were only allowed two hours of outdoor exercise per day with one other person or with household members, while indoor exercise venues were closed. On 2 August, a State of Disaster was declared, with metropolitan Melbourne moving into Stage 4 restrictions, which included no travel further than $5 \mathrm{~km}$ from home without a work permit. In Western Australia, non-work indoor gatherings allowed up to 100 people at any one time per single undivided space, up to a total of 300 people per venue, providing there was only one person per two square meters. New Zealand was at Alert Level 1-Prepare, with no restriction on personal movement.

Australian and New Zealand residents aged 18 years or older who were employed at the time of the survey were eligible to participate and provided their informed consent before commencing. No other inclusion or exclusion criteria were applied. The survey collected information on participant demographics and characteristics, including gender, age, ethnicity, marital status, education and employment history, height, weight, medical history, and dependent relationships. The survey also collected information on current health-related lifestyle behaviours, including smoking, alcohol consumption, PA, sleep quantity, and information on work ability, absenteeism, and presenteeism. The study was approved by the La Trobe University Human Research Ethics Committee (HEC10200) and is reported according to the STROBE Statement [24] (Appendix A). Data were collected and managed using the REDCap electronic data capture tool hosted at La Trobe University.

\subsection{Physical Activity and Exercise Participation}

Participants responded to 11 questions about their PA and sedentary behaviour over the past week. This information was collected using the short-form International Physical Activity Questionnaire (IPAQ) [25] and strength exercise questions that have been used in previous epidemiological research [10]. Moderate-vigorous intensity aerobic physical activity (MVPA) participation was calculated as weekly energy expenditure (MET-min. $\mathrm{wk}^{-1}$ ) using the validated IPAQ formula [26], and strength exercise participation was reported as the number of days in the past week that the participant performed muscle strengthening exercises. Aerobic and strength exercise participation were compared to current MVPA (i.e., $\geq 500 \mathrm{MET} \cdot \mathrm{min} \cdot \mathrm{week}^{-1}$ ) [8,27] and strength exercise ( $\geq 2$ days each week) [8] guidelines, respectively. Sedentary behaviour was reported as time spent sitting on a typical weekday during the last seven days.

\subsection{Other Lifestyle Behaviours}

Participants were asked whether or not they were a current smoker or if they had quit in the last six months and how often (if ever) they consumed alcohol. Participants were also asked how many hours of actual sleep they got at night on average over the last month, after reporting their usual bedtime, wake time, and the duration taken to typically fall asleep. 


\subsection{Work Ability}

Three questions from the Work Ability Index [28] were included. The first question, validated as a single item [29], asked participants to rate their current work ability compared to their lifetime best using an 11-point scale ranging from 0 (cannot work) to 10 (lifetime best). The next two questions asked participants to rate their current physical work ability with respect to the physical demands of their work and their current mental work ability with respect to the mental demands of their work, each using a 5-point scale ranging from 0 (very poor) to 4 (very good). To enable participants to respond accurately, Tengland's (2011, p. 275) definition of work ability was provided: "Having the occupational competence, the health required for the competence, and the occupational virtues that are required for managing the work tasks, assuming that the tasks are reasonable and that the work environment is acceptable" [30].

\subsection{Absenteeism and Presenteeism}

Absenteeism and presenteeism (constructs of employee productivity) over the past month were measured using the validated World Health Organisation's Heath and Work Performance Questionnaire following the provided instructions [31]. To measure absenteeism, participants reported their expected weekly hours of work and their actual number of hours of work over the past month after accounting for time off due to health reasons. This was converted to a measure of relative absenteeism, expressed as the difference between actual hours worked and expected hours of work, as a fraction of expected hours of work, and expressed as a percentage. Negative values indicated that participants worked more hours over the past month than what was expected of them. To measure presenteeism, participants were asked to rate their overall job performance on the days they worked over the past month using an 11-point scale ranging from 0 (total lack of job performance) to 10 (no lack of job performance), which was then expressed as a percentage (0-100\%). Presenteeism (i.e., lack of job performance) was calculated as the difference between the reported score and $100 \%$, with higher presenteeism values indicating poorer job performance.

\subsection{Statistical Analyses}

Univariate (unadjusted) and multivariate (adjusted for potential confounding variables including age, gender, ethnicity, marital status, level of education, employment level, employment group, BMI, number of medical conditions, medications, number of dependents, homeschool responsibilities, smoking status, alcohol consumption, sleep quantity and sedentary behaviour) regressions were used to investigate relationships between PA, mental and physical work ability, absenteeism, and presenteeism. Logistic regression was used for binary outcomes, and ordinal logistic regression for ordered categorical outcomes. The proportional odds assumption was checked and was met for the ordered logistic regressions. Quantile linear regression for the median was used for continuous outcomes. Quantile regression was chosen, as the assumptions behind ordinary linear regression were not met, namely normality and constancy of variance of the residuals. Non-linear fits were also checked for the continuous covariates in the quantile regressions, but the Akaike Information Criterion (AIC) indicated that linear functional forms were better fits. To arrive at a parsimonious model of best fit, a backward elimination process based on the AIC was used. Mean and 95\% confidence intervals (CIs) are reported unless otherwise indicated.

The Chi-Square test of association was used to investigate whether participants who reported meeting the MVPA guideline were more or less likely to be meeting the strength exercise guideline (and vice-versa), and to further investigate whether those with medical conditions or those in part-time employment were more or less likely to be meeting the MVPA or strength exercise guidelines, with the phi coefficient (correlation coefficient) indicating the effect size $(0.1=$ small, $0.3=$ moderate, $0.5=$ large $)$. The number of participant responses for each outcome is reported in each table. Data processing, chi-square, and $t$-tests were conducted with Stata (version 16.1, StataCorp LLC, College Station, TX, USA). The regressions were carried out in freeware $\mathrm{R}$ [32]. The ordered logistic regressions were 
conducted with the polr function from the MASS library [33]. The quantile regressions were conducted with the quantreg library ( $R$ package version 5.67) [34].

\section{Results}

\subsection{Participant Characteristics and Health-Related Behaviours}

Participant characteristics are provided in Table 1 . After checking against the inclusion criteria, 23 respondents were excluded from analyses as they were unemployed, leaving a final sample size of 433 . Most participants were female (75\%), aged $18-29(24.7 \%)$ or $30-39(30.3 \%)$ years, located in Victoria, Australia (51.4\%), were Oceanian (51.3\%), married $(46.8 \%)$, had completed an undergraduate degree or higher $(75.2 \%)$, had no dependents $(63.5 \%)$, had not homeschooled children during the pandemic $(72.5 \%)$, were employed full-time (69.7\%), and worked as professionals (58\%) (Tables 1 and 2). Approximately half of the participants were of a normal weight (54\%), and most were not taking any prescribed medications $(67.8 \%)$ (Table 3$)$. The most prevalent medical conditions reported were anxiety $(14.1 \%)$, depression $(11.1 \%)$, respiratory disease $(10.0 \%)$, and hypertension (5.3\%). Most participants were non-smokers $(96.3 \%)$, and $76.9 \%$ reported consuming alcohol monthly, with $57.7 \%$ consuming alcohol weekly (Table 3). Participants slept a median $7 \mathrm{~h}$ per night and spent a median $7.9 \mathrm{~h}$ in sedentary behaviour each weekday. Over the week preceding the survey, most participants $(60.5 \%)$ reported meeting the minimum MVPA guideline of $\geq 500 \mathrm{MET} \cdot \mathrm{min} \cdot$ week $^{-1}$ [27]; however, less than half $(45.9 \%)$ reported meeting the minimum strength exercise guideline of $\geq 2$ days each week (Table 4 ). A little over one-third of the participants met both exercise guidelines (37.2\%), while $30.8 \%$ met neither guideline.

Table 1. Descriptive characteristics of the participant sample.

\begin{tabular}{lcc}
\hline \multicolumn{1}{c}{ Variable } & $n$ & $\mathbf{( \% )}$ \\
\hline Total participant sample & 433 & 100 \\
Gender & & \\
Male & 101 & 23.3 \\
Female & 325 & 75.1 \\
Non-binary & 3 & 0.7 \\
Other & 4 & 0.9 \\
Age (years) & & \\
18-29 & 107 & 24.7 \\
30-39 & 131 & 30.3 \\
40-49 & 95 & 21.9 \\
50-59 & 75 & 17.3 \\
60+ & 25 & 5.8 \\
Residence & & \\
New Zealand & 17 & 3.7 \\
Australia & 416 & 96.3 \\
Victoria & 214 & 51.4 \\
Western Australia & 160 & 38.5 \\
New South Wales & 33 & 7.9 \\
Queensland & 3 & 0.7 \\
South Australia & 3 & 0.7 \\
Tasmania & 3 & 0.7 \\
Ethnicity & & \\
Oceanian & 222 & 51.3 \\
European & 166 & 38.3 \\
Asian & 25 & 4.8 \\
Other & 20 &
\end{tabular}


Table 1. Cont.

\begin{tabular}{|c|c|c|}
\hline Variable & $n$ & $(\%)$ \\
\hline \multicolumn{3}{|l|}{ Marital Status } \\
\hline Married & 198 & 46.8 \\
\hline Never married & 103 & 24.3 \\
\hline De facto & 90 & 21.3 \\
\hline Widowed/Divorced/Separated & 32 & 7.6 \\
\hline \multicolumn{3}{|l|}{ Level of Education } \\
\hline Postgraduate degree/Diploma & 185 & 42.8 \\
\hline University/College degree & 140 & 32.4 \\
\hline Certificate I-IV/Diploma/Advanced Diploma & 66 & 15.2 \\
\hline Completed secondary school & 33 & 7.6 \\
\hline Did not complete secondary school/other & 8 & 1.9 \\
\hline \multicolumn{3}{|l|}{ Number of Dependents } \\
\hline 0 & 273 & 63.5 \\
\hline 1 or 2 & 126 & 29.3 \\
\hline $3+$ & 31 & 7.2 \\
\hline \multicolumn{3}{|l|}{ Homeschooled children during COVID-19 } \\
\hline Yes & 118 & 27.5 \\
\hline No & 311 & 72.5 \\
\hline \multicolumn{3}{|c|}{$\begin{array}{l}\text { BMI, Body Mass Index (underweight, }<18.5 \mathrm{~kg} \cdot \mathrm{m}^{-2} ; \text { normal range, } 18.5-24.99 \mathrm{~kg} \cdot \mathrm{m}^{-2} ; \text { overweight, } 25.00-29.9 \\
\left.\mathrm{~kg} \cdot \mathrm{m}^{-2} ; \text { obese, } \geq 30.00 \mathrm{~kg} \cdot \mathrm{m}^{-2}\right) ; \text { CI, Confidence Interval; IQR, Interquartile range. }\end{array}$} \\
\hline Variable & $n$ & $(\%)$ \\
\hline \multicolumn{3}{|l|}{ Employment Fraction } \\
\hline Full-time & 302 & 69.7 \\
\hline Part-time & 131 & 30.3 \\
\hline \multicolumn{3}{|l|}{ Employment Group } \\
\hline Professionals & 251 & 58.0 \\
\hline Clerical and Administration Workers & 61 & 14.1 \\
\hline Managers & 57 & 13.2 \\
\hline Community and Personal Services Workers & 23 & 5.3 \\
\hline Sales Workers & 16 & 3.7 \\
\hline Technicians and Trades Workers & 13 & 3.0 \\
\hline Other & 12 & 2.8 \\
\hline
\end{tabular}

Table 3. Health status and health-related behaviours of the participant sample.

\begin{tabular}{lcc}
\hline \multicolumn{1}{c}{ Variable } & $\boldsymbol{n}$ & $\mathbf{( \% )}$ \\
\hline BMI Classification & & \\
Underweight & 4 & 1.0 \\
Normal weight & 223 & 54.0 \\
Overweight & 131 & 31.7 \\
Obese & 55 & 13.3 \\
Medical Conditions & 276 & 63.9 \\
0 & 136 & 31.4 \\
1 or 2 & 20 & 4.6 \\
3+ & & \\
Prescribed Medications & 139 & 32.2 \\
Yes & 293 & 67.8 \\
No & & \\
\hline
\end{tabular}


Table 3. Cont.

\begin{tabular}{|c|c|c|}
\hline Variable & $n$ & $(\%)$ \\
\hline \multicolumn{3}{|l|}{ Smoking Status } \\
\hline Not a smoker & 417 & 96.3 \\
\hline Current smoker & 16 & 3.7 \\
\hline \multicolumn{3}{|l|}{ Alcohol Consumption } \\
\hline 4-7 times per week & 47 & 10.9 \\
\hline 2-3 times per week & 110 & 25.5 \\
\hline Once per week & 92 & 21.3 \\
\hline 2-3 times per month & 54 & 12.5 \\
\hline Once per month & 29 & 6.7 \\
\hline A few times per year & 52 & 12.0 \\
\hline None in the last year & 17 & 3.9 \\
\hline Never & 31 & 7.2 \\
\hline Sleep Quantity: Median (IQR) & \multicolumn{2}{|c|}{$7.0(6.5-8.0)$} \\
\hline Sedentary Behaviour: Median (IQR) & & \\
\hline
\end{tabular}

Current smoker (current smoker or quit in the last six months); Medical conditions (number of diagnosed medical conditions); Prescribed medications (currently taking any prescribed medications); Sedentary behaviour (hours per weekday spent sitting); Sleep quantity (average hours per night).

Table 4. Aerobic and strength exercise participation.

\begin{tabular}{cccc}
\hline & \multicolumn{3}{c}{ Strength Exercise Participation: $\boldsymbol{n} \mathbf{( \% )}$} \\
\hline Moderate-vigorous aerobic & $<2$ days $\cdot \mathrm{wk}^{-1}$ & $\geq 2$ days $\mathrm{wk}^{-1}$ & Total \\
exercise participation, $n(\%)$ & $124(30.8)$ & $35(8.7)$ & $159(39.5)$ \\
$<500 \mathrm{MET}-\mathrm{min} \cdot \mathrm{wk}^{-1}$ & $94(23.3)$ & $150(37.2)$ & $244(60.5)$ \\
$\geq 500 \mathrm{MET}-\mathrm{min} \cdot \mathrm{wk}^{-1}$ & $218(54.1)$ & $185(45.9)$ & $403(100.0)$ \\
Total &
\end{tabular}

MET, Metabolic equivalent of energy expenditure.

\subsection{Relationships between Exercise Participation and Participant Characteristics}

Participants who met the MVPA guideline were significantly more likely to meet the strength exercise guideline, and vice-versa $(p<0.001$; phi coefficient effect size $=0.39$ (moderate)). Specifically, of the 244 participants who met the MVPA guideline, $150(61.5 \%)$ also met the strength exercise guideline. Of the 185 participants who met the strength exercise guideline, $150(81.1 \%)$ also met the MVPA guideline (Table 4$)$. Compared to those without a medical condition, those with one or more medical conditions were less likely to meet the MVPA guideline $(65.4 \%$ vs. $51.4 \%$; $p=0.008$; effect size $=0.14$ (small)) but no less likely to meet the strength exercise guideline. There was no difference in the proportion of full-time and part-time employees meeting the strength exercise guideline (44.4\% vs. $49.2 \%$ ); however, the difference between the two groups meeting the MVPA guideline approached statistical significance $(63.6 \%$ vs. $52.8 \% ; p=0.053$; effect size $=0.10$ (small)). Compared to full-time employees, more part-time employees were aged under 30 years $(29.0 \%$ vs. $22.8 \%$; $p=0.028$; effect size $=0.21$ (small) $)$, were female $(84.0 \%$ vs. $71.2 \%$; $p=0.018$; effect size $=0.17$ (small)), had one or more dependents for whom they provided primary care $(50.0 \%$ vs. $30.7 \% ; p=0.002$; effect size $=0.20$ (small)), and were responsible for homeschooling one or more children during COVID-19 (36.9\% vs. $23.4 \%$; $p=0.006$; effect size $=0.14($ small)), with no differences in marital status, medical conditions, or prescribed medications.

\subsection{Associations between Exercise Participation and Work Ability}

Current work ability $(n=349)$ was (median (IQR)) 20.0\% (10-30\%) below lifetime best, as were physical $(20 \%(0-20 \%))$ and mental work abilities $(20 \%(20-40 \%))$. Multivariate analyses determined that participants who met the MVPA guideline had (aOR (95\% CI)) $1.80(1.18-2.83 ; p=0.007)$ times greater odds of reporting rather good or very good mental work ability, and $2.10(1.34-3.29 ; p=0.001)$ times greater odds of reporting rather good 
or very good physical work ability (Table 5). Significant univariate associations were observed between meeting the strength exercise guideline and odds of reporting higher physical $(1.79(1.20-2.68) ; p=0.004)$ and mental $(1.50(1.03-2.19) ; p=0.035)$ work ability. However, these associations were attenuated in the multivariate models for physical (1.46 (0.94-2.27); $p=0.092)$ and mental (1.43 (0.94-2.18); $p=0.088)$ work ability. There was no significant association between number of medical conditions and mental work ability; however, participants with three or more medical conditions $(n=20)$ were $80 \%$ less likely (aOR $0.20(0.07-0.56) ; p=0.002)$ to report rather good or very good physical work ability than participants with no medical conditions. Those in part-time employment were $56 \%$ less likely (aOR $0.44(0.26-0.75) ; p=0.002$ ) to report rather good or very good mental work ability than those in full-time employment, but there was no significant association between employment fraction and physical work ability. Each 10\% increase in daily sedentary behaviour was associated with a $31 \%$ reduction in the odds of reporting good or very good mental work ability (aOR $0.69(0.59-0.81) ; p<0.0001)$. Furthermore, a $10 \%$ increase in daily sedentary behaviour was associated with $3.68 \%$ higher median presenteeism (95\% CI: $1.24-6.12 \% ; p=0.003)$. However, there was no significant association between sedentary behaviour and physical work ability ( $\mathrm{aOR}=0.72(0.1-4.98) ; p=0.74$ ) or absenteeism (median (95\% CI)) $-1.67 \%((-0.034,0.0003) ; p=0.053)$.

Table 5. Multivariate regression results.

\begin{tabular}{cccc}
\hline & Estimated Difference & 95\% CI & $p$ Value \\
\hline & Meeting vs. not meeting the MVPA guideline & \\
Physical Work Ability & 2.10 & $1.34-3.29$ & 0.001 \\
Mental Work Ability & 1.80 & $1.18-2.83$ & 0.007 \\
Relative Absenteeism & $-0.33 \%$ & $-5.00-4.00 \%$ & 0.880 \\
Absolute Presenteeism & $7.42 \%$ & $0.66-14.19 \%$ & 0.032 \\
Meeting vs. not meeting the strength exercise guideline \\
Physical Work Ability & 1.46 & $0.94-2.27$ & 0.092 \\
Mental Work Ability & 1.43 & $0.94-2.18$ & 0.088 \\
Relative Absenteeism & $1.25 \%$ & $-3.00-6.00 \%$ & 0.572 \\
Absolute Presenteeism & $2.80 \%$ & $-3.50-9.10 \%$ & 0.382
\end{tabular}

CI, Confidence Interval; $n=349$. Adjusted odds ratio reported for physical work ability and mental work ability. Median reported for absenteeism and presenteeism.

\subsection{Associations between Exercise Participation, Absenteeism, and Presenteeism}

Overall, participants $(n=349)$ reported working a median 4.0\% (IQR: 0-21.0\%) more hours over the previous month than what was expected of them (relative absenteeism) and reported a median 30.0\% (IQR: 20.0-40.0\%) lack of job performance (absolute presenteeism) over the same period. Compared to participants who did not meet the MVPA guideline, those who met the guideline reported a median $7.42 \%$ higher job performance $(95 \% \mathrm{CI}$ : $0.66-14.19 \% ; p=0.032$ ) (Table 5). However, those who met the strength exercise guideline did not report different job performance to those who did not meet the guideline (median $(95 \% \mathrm{CI}))+2.80 \%(-3.50-9.10 \% ; p=0.382)$. There were no differences in absenteeism for those meeting the MVPA (median $(95 \% \mathrm{CI}))-0.33 \%(-5.00-4.00 \% ; p=0.880)$ or strength exercise guideline (median $(95 \% \mathrm{CI})) 1.25 \%(-3.00-6.00 \% ; p=0.572)$ compared to those who did not meet the guidelines.

\section{Discussion}

Australian and New Zealand adult employees who reported meeting the MVPA guideline reported higher physical and mental work ability (i.e., occupational competence, health, and occupational virtues) and higher job performance compared to those who were not meeting the guideline during the early phase of the COVID-19 pandemic. Participants with one or more medical conditions were less likely to meet the MVPA guideline, while the difference between part-time (less likely) and full-time employees (more likely) approached statistical significance. 
The association between meeting the MVPA guideline and higher work ability was expected, as previous research has reported that higher PA is associated with better cognitive and physical function and greater mental and physical wellbeing in healthy adults in the workplace $[13,14,35]$. Our finding that participants who met the MVPA guideline reported higher job performance and work ability during the COVID-19 pandemic compared to those who did not meet the guideline is important, as other research has reported reduced job performance (i.e., greater presenteeism) in adults who transitioned from the workplace to working either fully or partly from home during this time [36]. Critically, though, the potential effect for PA to influence job performance during work from home was not investigated [36], as was the case in our study. Furthermore, software professionals working from home during the pandemic reported that distractions, boredom, and the need for competence were negatively associated with self-reported job performance, but in contrast to our findings, there was no association between job performance and PA [37]. Our findings suggest that engagement in PA can support employee job performance in changing work environments, which is an important consideration for employers.

General work ability was $20 \%$ below lifetime best, and participants reported working $4.0 \%$ hours more over the past month than usually required (i.e., overtime) but reported a $30.0 \%$ lack of job performance, which may reflect job-related [5] or other stress and may lead to poorer health outcomes over time [38]. Factors negatively affecting work ability have been identified as a lack of leisure time, vigorous PA, poor musculoskeletal health, older age, high mental work demands, and poor work environment [39]. During COVID-19, many employees were required to work from home, resulting in increased distractions and fewer peer-to-peer social interactions, potentially negatively affecting wellbeing during this time [5,37]. The pandemic also appears to have negatively impacted mental health, which could be a factor affecting work performance [1,4,5]. In addition, COVID-19 may have compounded already burdened employees with additional personal responsibilities while working from home, such as homeschooling or caring for relatives. For example, a survey of US employees working from home during the COVID-19 pandemic found that a reduction in physical and mental wellbeing was associated with several factors, including less exercise, having at least one child at home, distractions while working, less co-worker communication, higher workload, having to adjust work hours, and lower satisfaction with indoor workspace set-up [35]. Participants in our study may have been experiencing similar burdens, as they reported a $30 \%$ lack of job performance despite working more hours than was expected of them, noting that those who with higher MVPA participation reported lower presenteeism.

Part-time employees were less likely to meet the MVPA guideline than full-time employees and were less likely to report a rather good or very good mental work ability. Part-time employees were more likely to be female and reported having additional responsibilities; specifically, they were more likely to have caring and homeschooling responsibilities, which could have reduced their opportunities for PA participation. Given the evidence that increasing PA improves physical and mental work ability [20,21], part-time employees might require additional support to promote engagement in PA and exercise, particularly if they are not commuting to the workplace. Furthermore, those who had one or more medical conditions were less likely to meet the MVPA guidelines, while people with three or more medical conditions were less likely to report a rather good or very good physical work ability. Reports of severity of COVID-19 infection in individuals with existing medical conditions such as diabetes and obesity may have deterred individuals from completing MVPA for want of lowering their exposure risk, or those with medical conditions may have been less physically active as a result of their condition(s). Either way, employees with medical conditions might require additional exercise behaviour change support or education on how to exercise safely, particularly in these circumstances.

The amount of weekday sedentary behaviour that people reported $(\sim 7.9 \mathrm{~h})$ was similar to that of the average healthy adult population (median $8.2 \mathrm{~h}$ ) prior to the COVID19 pandemic [40]. Previous research in a similar population demonstrated that employees 
spend around $77 \%(\sim 6.6 \mathrm{~h})$ of their working hours and almost two-thirds $(\sim 4.3 \mathrm{~h})$ of non-working hours each weekday in sedentary behaviour [41], and sedentary time was potentially $50 \%$ greater in those working from home compared to those working at the workplace during the COVID-19 pandemic [3]. In our study, the likelihood of reporting poorer mental work ability and reduced job performance increased with increases in sedentary time.

The proportion of participants in this study who reported meeting the MVPA and strength exercise guidelines was higher than that reported in adult Australian and international populations prior to COVID-19 [9-11]. Other data have indicated that some people may have engaged in more PA because they had more time due to not having to commute to work and recognised the need to participate in regular PA during the pandemic [2]. Of the 185 participants who met the strength exercise guideline, $81.1 \%$ also met the MVPA guideline. This finding suggests that promoting strength exercise participation might be an effective strategy to increase adherence to both the MVPA and strength exercise guidelines when movement and social restrictions are in place. With appropriate education, strength exercise in the form of using body weight as resistance can be easily completed in the home, allowing people with existing medical conditions to restrict potential exposure to COVID-19 while increasing their PA participation.

It must be acknowledged that the results are only generalisable to the sample included in the survey and not the wider working population. Furthermore, there are limitations with the use of the self-reporting tools to collect data on PA, and the IPAQ measures PA over the past 7 days, whereas presenteeism and absenteeism were measured over the past month. The specific restrictive measures implemented across Australia and New Zealand differed between jurisdictions throughout the survey period, and it is possible that movement and social restrictions changed between the earliest date requested to consider activities in the survey tools and when the respondent completed the survey. Therefore, it is not clear how the current level of restriction in relation to any previous restrictions influenced outcomes, and a decision was made not to include degree of restriction as a covariate.

\section{Conclusions}

During the early phase of the COVID-19 pandemic, with various movement and social restrictions placed on adult employees in Australia and New Zealand, meeting the MVPA guideline was associated with greater odds of reporting good physical and mental work ability and higher job performance. Furthermore, higher sedentary behaviour was associated with lower reported mental work ability and job performance. These findings support the idea that employees should be provided opportunities and encouraged to participate in regular exercise, as this has the potential to benefit both employers (higher productivity) and employees (higher work ability and health outcomes). Physical work ability and MVPA were lower in those with existing medical conditions, while mental work ability and MVPA were lower in part-time employees. These populations may require additional physical activity health behaviour support to begin and sustain regular exercise participation, and future interventions should account for this in their design. To ensure acceptable levels of presenteeism and promote good work ability, employers should promote and educate employees on safe exercise strategies at the workplace and when working from home to assist with managing work and general stressors during a changing and uncertain global environment.

Author Contributions: Conceptualization, J.R.H., R.M.M., A.C., H.T.S., M.I.K. and B.A.G.; methodology, J.R.H., R.M.M., A.C., H.T.S., D.V. and B.A.G.; software, J.R.H. and D.V.; formal analysis, D.V.; investigation, J.R.H., R.M.M. and D.V.; resources, J.R.H., R.M.M., A.C., H.T.S. and D.V.; data curation, J.R.H., R.M.M. and D.V.; writing—original draft preparation, J.R.H., R.M.M., A.C., H.T.S., D.V., M.I.K. and B.A.G.; writing—review and editing, J.R.H., R.M.M., A.C., H.T.S., D.V., M.I.K. and B.A.G.; project administration, J.R.H.; All authors have read and agreed to the published version of the manuscript. 
Funding: This research received funding from the Holsworth Research Initiative, La Trobe University.

Institutional Review Board Statement: The study was conducted according to the guidelines of the Declaration of Helsinki and approved by the Ethics Committee of La Trobe University (HEC10200) on 25 May 2020.

Informed Consent Statement: Informed consent was obtained from all subjects involved in the study.

Data Availability Statement: The data presented in this study are openly available in La Trobe University's Institutional Repository (OPAL) at doi:10.26181/619d8d4a12349.

Acknowledgments: The authors thank the respondents for their contribution to the study and would like to acknowledge the Bendigo Tertiary Education Anniversary Foundation and Holsworth Research Initiative's support of Michael Kingsley's research.

Conflicts of Interest: The authors declare no conflict of interest.

\section{Appendix A}

Table A1. STROBE Checklist.

\begin{tabular}{|c|c|c|c|}
\hline & Item No. & Recommendation & Page No. \\
\hline \multirow[t]{2}{*}{ Title and abstract } & \multirow[t]{2}{*}{1} & $\begin{array}{l}\text { (a) Indicate the study's design with a commonly used term in the } \\
\text { title or the abstract }\end{array}$ & 1 \\
\hline & & $\begin{array}{l}\text { (b) Provide in the abstract an informative and balanced summary of } \\
\text { what was done and what was found }\end{array}$ & 1 \\
\hline \multicolumn{4}{|c|}{ Introduction } \\
\hline Background/rationale & 2 & $\begin{array}{l}\text { Explain the scientific background and rationale for the } \\
\text { investigation being reported }\end{array}$ & 2 \\
\hline Objectives & 3 & State specific objectives, including any prespecified hypotheses & 2 \\
\hline \multicolumn{4}{|c|}{ Methods } \\
\hline Study design & 4 & Present key elements of study design early in the paper & $2-3$ \\
\hline Setting & 5 & $\begin{array}{l}\text { Describe the setting, locations, and relevant dates, including } \\
\text { periods of recruitment, exposure, follow-up, and data collection }\end{array}$ & $2-3$ \\
\hline Participants & 6 & $\begin{array}{l}\text { Cross-sectional study-Give the eligibility criteria, and the sources } \\
\text { and methods of selection of participants }\end{array}$ & 3 \\
\hline Variables & 7 & $\begin{array}{l}\text { Clearly define all outcomes, exposures, predictors, potential } \\
\text { confounders, and effect modifiers. Give diagnostic criteria, if } \\
\text { applicable }\end{array}$ & $3-4$ \\
\hline Data sources/ measurement & $8^{*}$ & $\begin{array}{l}\text { For each variable of interest, give sources of data and details of } \\
\text { methods of assessment (measurement). Describe comparability of } \\
\text { assessment methods if there is more than one group }\end{array}$ & $3-4$ \\
\hline Bias & 9 & Describe any efforts to address potential sources of bias & $2-4$ \\
\hline Study size & 10 & Explain how the study size was arrived at & 3 \\
\hline Quantitative variables & 11 & $\begin{array}{l}\text { Explain how quantitative variables were handled in the analyses. If } \\
\text { applicable, describe which groupings were chosen and why }\end{array}$ & $4-5$ \\
\hline \multirow{5}{*}{ Statistical methods } & \multirow{5}{*}{12} & $\begin{array}{l}\text { (a) Describe all statistical methods, including those used to control } \\
\text { for confounding }\end{array}$ & $4-5$ \\
\hline & & $\begin{array}{l}\text { (b) Describe any methods used to examine subgroups and } \\
\text { interactions }\end{array}$ & $4-5$ \\
\hline & & (c) Explain how missing data were addressed & 5 \\
\hline & & $\begin{array}{c}\text { Cross-sectional study - If applicable, describe analytical methods } \\
\text { taking account of sampling strategy }\end{array}$ & $4-5$ \\
\hline & & (e) Describe any sensitivity analyses & $4-5$ \\
\hline
\end{tabular}


Table A1. Cont.

\begin{tabular}{|c|c|c|c|}
\hline & Item No. & Recommendation & Page No. \\
\hline \multicolumn{4}{|c|}{ Results } \\
\hline \multirow[t]{3}{*}{ Participants } & \multirow[t]{3}{*}{13 * } & $\begin{array}{l}\text { (a) Report numbers of individuals at each stage of study-e.g., numbers } \\
\text { potentially eligible, examined for eligibility, confirmed eligible, included in } \\
\text { the study, completing follow-up, and analysed }\end{array}$ & 5 \\
\hline & & (b) Give reasons for non-participation at each stage & 5 \\
\hline & & (c) Consider use of a flow diagram & $\mathrm{N} / \mathrm{A}$ \\
\hline \multirow[t]{2}{*}{ Descriptive data } & \multirow[t]{2}{*}{$14^{*}$} & $\begin{array}{l}\text { (a) Give characteristics of study participants (e.g., demographic, clinical, } \\
\text { social) and information on exposures and potential confounders }\end{array}$ & $5-7$ \\
\hline & & $\begin{array}{l}\text { (b) Indicate number of participants with missing data for each variable of } \\
\text { interest }\end{array}$ & $5-8$ \\
\hline Outcome data & $15^{*}$ & $\begin{array}{c}\text { Cross-sectional study-Report numbers of outcome events or summary } \\
\text { measures }\end{array}$ & $5-8$ \\
\hline \multirow[t]{3}{*}{ Main results } & \multirow[t]{3}{*}{16} & $\begin{array}{l}\text { (a) Give unadjusted estimates and, if applicable, confounder-adjusted } \\
\text { estimates and their precision (e.g., } 95 \% \text { confidence interval). Make clear } \\
\text { which confounders were adjusted for and why they were included }\end{array}$ & 8 \\
\hline & & $\begin{array}{c}\text { (b) Report category boundaries when continuous variables were } \\
\text { categorized }\end{array}$ & $\mathrm{N} / \mathrm{A}$ \\
\hline & & $\begin{array}{l}\text { (c) If relevant, consider translating estimates of relative risk into absolute } \\
\text { risk for a meaningful time period }\end{array}$ & $\mathrm{N} / \mathrm{A}$ \\
\hline Other analyses & 17 & $\begin{array}{l}\text { Report other analyses done-e.g., analyses of subgroups and interactions, } \\
\text { and sensitivity analyses }\end{array}$ & $7-8$ \\
\hline \multicolumn{4}{|c|}{ Discussion } \\
\hline Key results & 18 & Summarise key results with reference to study objectives & 9 \\
\hline Limitations & 19 & $\begin{array}{l}\text { Discuss limitations of the study, taking into account sources of potential } \\
\text { bias or imprecision. Discuss both direction and magnitude of any potential } \\
\text { bias }\end{array}$ & 10 \\
\hline Interpretation & 20 & $\begin{array}{c}\text { Give a cautious overall interpretation of results considering objectives, } \\
\text { limitations, multiplicity of analyses, results from similar studies, and other } \\
\text { relevant evidence }\end{array}$ & $10-11$ \\
\hline Generalisability & 21 & Discuss the generalisability (external validity) of the study results & 10 \\
\hline \multicolumn{4}{|c|}{ Other information } \\
\hline Funding & 22 & $\begin{array}{l}\text { Give the source of funding and the role of the funders for the present study } \\
\text { and, if applicable, for the original study on which the present article is } \\
\text { based }\end{array}$ & 11 \\
\hline
\end{tabular}

Reprinted from von Elm et al. (2007) [24]. * Give information separately for cases and controls in case-control studies and, if applicable, for exposed and unexposed groups in cohort and cross-sectional studies. Note: An Explanation and Elaboration article discusses each checklist item and gives methodological background and published examples of transparent reporting. The STROBE checklist is best used in conjunction with this article (freely available on the Web sites of PLoS Medicine at, Annals of Internal Medicine at http: / /www.annals.org/ (accessed on 21 August 2021), and Epidemiology at http:/ /www.epidem.com/ (accessed on 21 August 2021)). Information on the STROBE Initiative is available at www.strobe-statement.org (accessed on 21 August 2021).

\section{References}

1. Meyer, J.; McDowell, C.; Lansing, J.; Brower, C.; Smith, L.; Tully, M.; Herring, M. Changes in physical activity and sedentary behaviour due to the COVID-19 outbreak and associations with mental health in 3,052 US adults. Camb. Open Engage 2020, 17, 6469. [CrossRef]

2. Meiring, R.M.; Gusso, S.; McCullough, E.; Bradnam, L. The Effect of the COVID-19 Pandemic Movement Restrictions on Self-Reported Physical Activity and Health in New Zealand: A Cross-Sectional Survey. Int. J. Environ. Res. Public Health 2021, 18, 1719. [CrossRef] [PubMed]

3. Fukushima, N.; Machida, M.; Kikuchi, H.; Amagasa, S.; Hayashi, T.; Odagiri, Y.; Takamiya, T.; Inoue, S. Associations of working from home with occupational physical activity and sedentary behavior under the COVID-19 pandemic. J. Occup. Health. 2021, 63, e12212. [CrossRef] [PubMed] 
4. Oakman, J.; Kinsman, N.; Stuckey, R.; Graham, M.; Weale, V. A rapid review of mental and physical health effects of working at home: How do we optimise health? BMC Public Health 2020, 20, 1825. [CrossRef]

5. Van Der Feltz-Cornelis, C.M.; Varley, D.; Allgar, V.L.; de Beurs, E. Workplace Stress, Presenteeism, Absenteeism, and Resilience Amongst University Staff and Students in the COVID-19 Lockdown. Front. Psychiatry 2020, 11, 588803. [CrossRef]

6. Haskell, W.L.; Blair, S.N.; Hill, J.O. Physical activity: Health outcomes and importance for public health policy. Prev. Med. 2009, 49, 280-282. [CrossRef]

7. Tremblay, M.S.; Colley, R.C.; Saunders, T.J.; Healy, G.N.; Owen, N. Physiological and health implications of a sedentary lifestyle. Appl. Physiol. Nutr. Metab. 2010, 35, 725-740. [CrossRef]

8. Bull, F.C.; Al-Ansari, S.S.; Biddle, S.; Borodulin, K.; Buman, M.P.; Cardon, G.; Carty, C.; Chaput, J.-P.; Chastin, S.; Chou, R.; et al. World Health Organization 2020 guidelines on physical activity and sedentary behaviour. Br. J. Sports Med. 2020, 54, 1451-1462. [CrossRef]

9. Ozemek, C.; Lavie, C.J.; Rognmo, Ø. Global physical activity levels-Need for intervention. Prog. Cardiovasc. Dis. 2019, 62, 102-107. [CrossRef]

10. Bennie, J.A.; Pedisic, Z.; van Uffelen, J.G.; Gale, J.; Banting, L.K.; Vergeer, I.; Stamatakis, E.; Bauman, A.E.; Biddle, S.J. The descriptive epidemiology of total physical activity, muscle-strengthening exercises and sedentary behaviour among Australian adults-results from the National Nutrition and Physical Activity Survey. BMC Public Health 2016, 16, 73. [CrossRef]

11. Australian Institute of Health and Welfare. Insufficient Physical Activity; AIHW: Canberra, Australia, 2020.

12. Ding, D.; Lawson, K.D.; Kolbe-Alexander, T.L.; Finkelstein, E.A.; Katzmarzyk, P.T.; van Mechelen, W.; Pratt, M. The economic burden of physical inactivity: A global analysis of major non-communicable diseases. Lancet 2016, 388, 1311-1324. [CrossRef]

13. Nawrocka, A.; Garbaciak, W.; Cholewa, J.; Mynarski, W. The relationship between meeting of recommendations on physical activity for health and perceived work ability among white-collar workers. Eur. J. Sport Sci. 2018, 1-8. [CrossRef]

14. Calatayud, J.; Jakobsen, M.D.; Sundstrup, E.; Casaña, J.; Andersen, L.L. Dose-response association between leisure time physical activity and work ability: Cross-sectional study among 3000 workers. Scand. J. Public Health 2015, 43, 819-824. [CrossRef]

15. Oakman, J.; Neupane, S.; Proper, K.I.; Kinsman, N.; Nygård, C.-H. Workplace interventions to improve work ability: A systematic review and meta-analysis of their effectiveness. Scand. J. Work. Environ. Health 2018, 44, 134-146. [CrossRef]

16. Grimani, A.; Aboagye, E.; Kwak, L. The effectiveness of workplace nutrition and physical activity interventions in improving productivity, work performance and workability: A systematic review. BMC Public Health 2019, 19, 1676. [CrossRef]

17. Yeung, O.; Johnston, K. The Future of Wellness at Work; Global Wellness Institute: Miami, FL, USA, 2016.

18. López-Bueno, R.; Smith, L.; Andersen, L.L.; López-Sánchez, G.F.; Casajús, J.A. Association between physical activity and sickness absenteeism in university workers. Occup. Med. 2019, 70, 24-30. [CrossRef]

19. Justesen, J.B.; Søgaard, K.; Dalager, T.; Christensen, J.R.; Sjøgaard, G. The effect of intelligent physical exercise training on sickness presenteeism and absenteeism among office workers. J. Occup. Environ. Med. 2017, 59, 942-948. [CrossRef]

20. Sundstrup, E.; Jakobsen, M.D.; Brandt, M.; Jay, K.; Persson, R.; Aagaard, P.; Andersen, L.L. Workplace strength training prevents deterioration of work ability among workers with chronic pain and work disability: A randomized controlled trial. Scand. J. Work. Environ. Health 2014, 40, 244-251. [CrossRef]

21. Haufe, S.; Kerling, A.; Protte, G.; Bayerle, P.; Stenner, H.T.; Rolff, S.; Sundermeier, T.; Kück, M.; Ensslen, R.; Nachbar, L. Telemonitoring-supported exercise training, metabolic syndrome severity, and work ability in company employees: A randomised controlled trial. Lancet Public Health 2019, 4, e343-e352. [CrossRef]

22. Harris, P.A.; Taylor, R.; Minor, B.L.; Elliott, V.; Fernandez, M.; O’Neal, L.; McLeod, L.; Delacqua, G.; Delacqua, F.; Kirby, J.; et al. The REDCap consortium: Building an international community of software platform partners. J. Biomed. Inform. 2019, 95, 103208. [CrossRef]

23. Harris, P.A.; Taylor, R.; Thielke, R.; Payne, J.; Gonzalez, N.; Conde, J.G. Research electronic data capture (REDCap)—A metadatadriven methodology and workflow process for providing translational research informatics support. J. Biomed. Inform. 2009, 42, 377-381. [CrossRef] [PubMed]

24. von Elm, E.; Altman, D.G.; Egger, M.; Pocock, S.J.; Gøtzsche, P.C.; Vandenbroucke, J.P. The Strengthening the Reporting of Observational Studies in Epidemiology (STROBE) statement: Guidelines for reporting observational studies. Lancet 2007, 370, 1453-1457. [CrossRef]

25. International Physical Activity Questionnaire Group International Physical Activity Questionnaire. Available online: https: // sites.google.com/site/theipaq/ (accessed on 10 February 2021).

26. Craig, C.L.; Marshall, A.L.; Sjostrom, M.; Beauman, A.E.; Booth, M.L.; Ainsworth, B.E.; Pratt, M.; Ekelund, U.; Yngve, A.; Sallis, J.F.; et al. International physical activity questionnaire: 12-country reliability and validity. Med. Sci. Sports Exerc. 2003, 35, 1381-1395. [CrossRef] [PubMed]

27. Garber, C.E.; Blissmer, B.; Deschenes, M.R.; Franklin, B.; Lamonte, M.J.; Lee, I.-M.; Nieman, D.C.; Swain, D.P. Quantity and quality of exercise for developing and maintaining cardiorespiratory, musculoskeletal, and neuromotor fitness in apparently healthy adults: Guidance for prescribing exercise. Med. Sci. Sports Exerc. 2011, 43, 1334-1359. [CrossRef]

28. Tuomi, K.; Ilmarinen, J.; Jahkola, A.; Katajarinne, L.; Tulkki, A. Work Ability Index, 2nd ed.; Institute of Occupational Health: Helsinki, Finland, 2006. 
29. Ahlstrom, L.; Grimby-Ekman, A.; Hagberg, M.; Dellve, L. The work ability index and single-item question: Associations with sick leave, symptoms, and health-a prospective study of women on long-term sick leave. Scand. J. Work. Environ. Health 2010, 36, 404-412. [CrossRef]

30. Tengland, P.A. The concept of work ability. J Occup. Rehabil. 2011, 21, 275-285. [CrossRef]

31. Kessler, R.C.; Barber, C.; Beck, A.; Berglund, P.; Cleary, P.D.; McKenas, D.; Pronk, N.; Simon, G.; Stang, P.; Ustun, T.B. The World Health Organization Health and Work Performance Questionnaire (HPQ). J. Occup. Environ. Med. 2003, 45, 156-174. [CrossRef]

32. R Core Team R: A Language and Environment for Statistical Computing. Available online: https://www.r-project.org/ (accessed on 20 September 2020).

33. Venables, W.N.; Ripley, B.D. Modern Applied Statistics with S, 4th ed.; Springer: New York, NY, USA, 2002.

34. Koenker, R. quantreg: Quantile Regression. Available online: https: / CRAN.R-project.org/package=quantreg (accessed on 20 September 2020).

35. Xiao, Y.; Becerik-Gerber, B.; Lucas, G.; Roll, S.C. Impacts of working from home during COVID-19 pandemic on physical and mental well-being of office workstation users. J. Occup. Environ. Med. 2021, 63, 181. [CrossRef]

36. Weitzer, J.; Papantoniou, K.; Seidel, S.; Klösch, G.; Caniglia, G.; Laubichler, M.; Bertau, M.; Birmann, B.; Jäger, C.; Zenk, L.; et al. Working from home, quality of life, and perceived productivity during the first 50-day COVID-19 mitigation measures in Austria: A cross-sectional study. Int. Arch. Occup. Environ. Health 2021, 94, 1823-1827. [CrossRef]

37. Russo, D.; Hanel, P.H.P.; Altnickel, S.; Van Berkel, N. Predictors of well-being and productivity among software professionals during the COVID-19 pandemic-A longitudinal study. Empir. Softw. Eng. 2021, 26, 62. [CrossRef]

38. Kivimäki, M.; Kawachi, I. Work Stress as a Risk Factor for Cardiovascular Disease. Curr. Cardiol. Rep. 2015, 17, 74. [CrossRef]

39. van den Berg, T.; Elders, L.; de Zwart, B.; Burdorf, A. The effects of work-related and individual factors on the Work Ability Index: A systematic review. Occup. Environ. Med. 2008, 66, 211-220. [CrossRef]

40. Bauman, A.E.; Petersen, C.B.; Blond, K.; Rangul, V.; Hardy, L.L. The descriptive epidemiology of sedentary behaviour. In Sedentary Behaviour Epidemiology; Springer: Cham, Switzerland, 2018; pp. 73-106.

41. Thorp, A.A.; Healy, G.N.; Winkler, E.; Clark, B.K.; Gardiner, P.A.; Owen, N.; Dunstan, D.W. Prolonged sedentary time and physical activity in workplace and non-work contexts: A cross-sectional study of office, customer service and call centre employees. Int. J. Behav. Nutr. Phys. Act. 2012, 9, 1-9. [CrossRef] 